\title{
Complementary and Alternative Medical Practices: Training, Experience, and Attitudes of a Primary Care Medical School Faculty
}

\author{
Stephen M. Levine, MA,t Margaret L. Weber-Levine, PhD, and \\ Robert M. Mayberry, MPH, PhD
}

Background: Interest in alternative and complementary medical practices has grown considerably in recent years. Previous surveys have examined attitudes of the general public and practicing physicians. This study examined the training, experience, and attitudes of medical school faculty, who have the primary responsibility for the education of future family physicians.

Methods: A 24-item, self-administered questionnaire was distributed to all 200 faculty at a medical school with a mission of training primary care physicians.

Results: Of 30 therapies listed, 5 were considered legitimate medical practices by more than $70 \%$ of the faculty. Eighty-five percent of the respondents reported some training in alternative medical therapies, and $62 \%$ were interested in additional training. Eighty-three percent of the faculty reported personal experience with alternative therapies and most rated these as effective. Eighty-five percent of the respondents indicated that their general attitude toward alternative medicine is positive.

Conclusions: The results indicate that respondents have had substantial exposure to complementary therapies, are interested in learning more about these therapies, and have generally positive attitudes toward alternative medical practices and their use. Because of the role of these therapies in prevention, the positive attitudes might reflect the mission of this medical school to train primary care physicians. (J Am Board Fam Pract 2003;16:318-26.)

Interest in alternative and complementary medical practices has grown considerably in recent years. This interest has been seen in government, the general population, and among practicing physicians. The National Institutes of Health established the Office of Alternative Medicine in 1992, which in 1998 became the National Center for Complementary and Alternative Medicine, with a budget of $\$ 104.6$ million for fiscal year 2002. The use of alternative or complementary therapies by the US population appears to be substantial. ${ }^{1-4}$ In surveys of the general population, Eisenberg and colleagues $^{1,2}$ reported that in 1990 such therapies were

Submitted, revised, 11 October 2002.

From the Public Health Sciences Institute (SML) and the Department of Psychology (MLW-L) Morehouse College; and the Morehouse Medical Treatment Effectiveness Center (SML, RMM), Morehouse School of Medicine, Atlanta, Ga. Address reprint requests to Margaret L. Weber-Levine, PhD, Department of Psychology, Morehouse College, 830 Westview Dr SW, Atlanta, GA 30314.

This research was funded by a grant from the Agency for Health Care Policy and Research (HS07400) to the Morehouse Medical Treatment Effectiveness Center (MMEDTEC), Morehouse School of Medicine, Atlanta, Ga.

†Stephen M. Levine was killed in an aircraft accident shortly before this manuscript was submitted for publication. used by an estimated 34\% of the population, increasing to $42 \%$ in 1997 . According to their surveys, more visits were made to alternative medical practitioners than to all the primary care physicians in those years and the out-of-pocket outlay closely rivaled $^{1}$ or exceeded ${ }^{2}$ similar payments for all hospitalizations for the same periods.

A survey by Berman and colleagues ${ }^{5}$ of 295 family physicians in the Chesapeake Bay region found that most family physicians surveyed considered many alternative practices legitimate, and most expressed interest in receiving training in multiple alternative therapies. Other studies ${ }^{6,7}$ report that from $50 \%$ to $70 \%$ of primary care physicians refer their patients to alternative medical practitioners. There have been few other studies evaluating the attitudes of US physicians toward alternative and complementary health practices ${ }^{8-10}$ and conflicting reports of increasing, ${ }^{5}$ decreasing, ${ }^{11}$ or cautiously ${ }^{10}$ positive attitudes of practicing physicians toward alternative medicine make the clear documentation of current trends an important topic.

Because the medical school faculty has the primary responsibility for the education and training 
of future physicians, the faculty knowledge, experience, and attitudes on this topic are important factors in physician training. Whereas more than 60 medical schools $^{12}$ are currently offering at least one elective course on alternative medical therapies, the literature concerning medical school faculty attitudes is scarce. Burg and colleagues ${ }^{13}$ offer the only survey of a health science center faculty on this topic. Their study elicited data regarding personal use of and referral for 10 alternative therapies. The survey results indicated that more than one half of the health science center faculty have used alternative therapies themselves and that they were even more likely to recommend alternative therapies to patients.

The Burg et $\mathrm{al}^{13}$ study provides a step forward on this important topic; however, their survey is limited to personal use of and referral to only 10 alternative practices. The present study was designed to assess training, experience, and attitudes of a medical school faculty toward a wider range of alternative medical practices and to determine their interest in training or research in these practices. The survey was conducted at an historically black medical school with a mission of training primary care physicians and included 30 different complementary or alternative medical practices.

\section{Methods}

\section{Procedure}

A 24-item, self-administered questionnaire was mailed to all the 200 full- and part-time faculty at the Morehouse School of Medicine at the beginning of the fall 1996 semester. A cover letter from the dean encouraging participation was included. Two additional mailings, 3 weeks apart, also with follow-up letters from the dean, were sent to nonrespondents. One week after the last mailing, three telephone calls were made to each nonrespondent in an attempt to get their responses.

\section{Survey Instrument}

The questionnaire consisted of 24 items intended to address unresolved issues raised by previous published articles, items that might be unique to a medical school environment, and questions asked in previously published reports. For the purpose of this survey, the phrase "alternative/complementary medicine or therapies" referred to any substance, activity, or practice not usually taught in detail or recommended to medical students.

To provide some basis for comparison, the first three items were structured to follow closely items reported in previous studies. ${ }^{5,14}$ Each of these items contained an identical list of 30 specific alternative or complementary medical therapies. For the first question, the respondents evaluated each therapy as either a legitimate medical practice, belonging outside medicine, or not sure. The second item asked the respondents to indicate how much training they have had (none, some, a lot or advanced) in each therapy and in which they would like to receive training or additional training. The third item had the respondents check those therapies with which they have had personal experience and evaluate the effectiveness of those using the categories, effective, not effective, harmful, or unknown. The other 21 items were in the form of statements with a 7-point Likert-type scale (strongly agree, agree, agree somewhat, no opinion, disagree somewhat, disagree, and strongly disagree). The agreedisagree statements reported here can be loosely grouped into three categories relating to alternative medical therapies: (1) general attitude, (2) placebo effects, and (3) use. The questionnaire also contained 12 demographic items relating to age, sex, ethnicity, degree, and specialty.

\section{Data Analysis}

The survey data were entered and verified using Epi Info and analyzed with SPSS. ${ }^{15}$ The response rate for individual questions varied somewhat; therefore, analyses ignore blank or missing values except where noted. In those cases where respondents reported more than one degree, the highest degree earned was used to classify the data. The category "other degree" indicates those respondents with master degrees and/or doctorates other than the $\mathrm{MD}$ or $\mathrm{PhD}$. A general linear model ${ }^{15}$ (GLM) analysis was used to separate the shared effects of demographic factors on training, experience, and attitudes. The relation of demographic factors to the survey items is reported only where they are significant by this analysis.

\section{Results}

One hundred forty-six questionnaires were returned, of which 143 were usable, resulting in a response rate of $72 \%$. 
Table 1. Percentage of Respondents with Demographic Characteristics, by Academic Degrees.

\begin{tabular}{lcccc}
\hline $\begin{array}{l}\text { Demographic } \\
\text { Characteristic }\end{array}$ & $\begin{array}{c}\mathrm{MD} \\
(\mathrm{n}=75)\end{array}$ & $\begin{array}{c}\mathrm{PhD} \\
(\mathrm{n}=48)\end{array}$ & $\begin{array}{c}\text { Other } \\
\text { Degree } \\
(\mathrm{n}=20)\end{array}$ & $\begin{array}{c}\text { Total } \\
(\mathrm{n}=143)\end{array}$ \\
\hline Sex, male & 65 & 63 & 33 & 60 \\
Age, years & & & & \\
$\quad<36$ & 9 & 8 & 20 & 11 \\
$36-45$ & 56 & 32 & 45 & 46 \\
$46-55$ & 16 & 47 & 30 & 28 \\
$\geq 56$ & 19 & 13 & 5 & 15 \\
Ethnicity & & & & \\
$\quad$ African American & 74 & 48 & 75 & 66 \\
Asian & 16 & 17 & 10 & 16 \\
$\quad$ White & 7 & 28 & 10 & 14 \\
Other & 3 & 7 & 5 & 4 \\
\hline
\end{tabular}

Note: 143 responses were received from 200 questionnaires for a $72 \%$ response rate.

\section{Demographic Characteristics}

The demographic characteristics of the study respondents are displayed in Table 1. Sixty percent of the responding faculty were male. Men predominated among the doctor of medicine (MD) and academic doctorate $(\mathrm{PhD})$ faculty $(65 \%$ and $63 \%$ respectively) whereas the other degree faculty were largely women (67\%). Forty-six percent of the respondents were between the ages of 36 and 45 years. The $\mathrm{PhD}$ faculty were older, with $60 \%$ older than 46 years of age compared with $35 \%$ of the MD and other degree faculty. The medical specialties with the most respondents were medicine (40\%), pediatrics $(12 \%)$, and family practice $(11 \%)$. No other specialty exceeded $10 \%$. Almost one half of the MD respondents (49\%) reported a private practice. The $\mathrm{PhD}$ faculty had been teaching in a medical school environment longer than either MD or other faculty (mean 14 years, 10 years, and 7 years, respectively). Nearly $90 \%$ of all the respondents spent at least some of their time teaching.

African Americans made up 66\% of the faculty. The ethnic, sex, and degree characteristics of the responding sample closely match those of the faculty at large.

\section{Perceived Legitimacy, Training, and Personal Experience}

Perceived Legitimacy

Five therapies (nutrition and diet, counseling or psychotherapy, fitness and exercise, emotional support groups, and biofeedback) were considered legitimate medical practices by more than $70 \%$ of the respondents (Table 2). An additional 6 therapies (acupuncture, herbal medicine, massage therapy, chiropractic, hypnotherapy, and meditation) were considered a legitimate medical practice by more than $50 \%$ of the faculty. On the other hand, 9 therapies were given this classification by less than $25 \%$ of the responders (colon therapy, naturopathic medicine, macrobiotic diet, therapeutic touch, bioelectromagnetics, tai chi, Ayurvedic medicine, aromatherapy, and Reiki). African Americans and whites rated significantly more (GLM $P=.03$ ) of these therapies as legitimate than did Asian and other respondents.

\section{Training}

When asked to indicate whether they had any training (some, a lot or advanced, Table 2) in the same list of 30 alternative medical therapies, the 5 most frequently cited were nutrition and diet, fitness and exercise, counseling or psychotherapy, emotional support groups, and meditation. Eightyfive percent of the respondents reported at least some training in 1 or more alternative medical therapies, while $50 \%$ claimed either a lot or advanced levels. When the 5 alternative medical therapies most frequently classified as legitimate medical practices (nutrition and diet, counseling or psychotherapy, fitness and exercise, emotional support groups, and biofeedback) were removed from this analysis, $71 \%$ of those responding nonetheless indicated at least some training in at least 1 therapy, and $29 \%$ of the faculty reported a lot or advanced training. Of this latter group, one half were medical doctors (28\% of the total MD respondents). The $\mathrm{PhD}$ respondents indicated having had training in significantly fewer of these therapies than either the MD or other degree respondents (GLM $P=.038$ ).

Respondents were most interested in receiving training in nutrition and diet, herbal medicine, and biofeedback. Meditation, acupuncture, and fitness and exercise tied for fourth place (Table 2). Whereas $62 \%$ of all respondents wanted training in at least 1 of the 30 alternative medical therapies, $34 \%$ indicated a desire for training in 5 or more therapies. Forty-eight percent of the respondents indicated a desire for further training in a therapy in which they already have had some level of training.

\section{Personal Experience and Perceived Effectiveness}

Eighty-three percent (118) of the faculty reported having had a personal experience with 1 or more 
Table 2. Percentage of Respondents Indicating Perceived Legitimacy of Alternative Therapies, and Amount of Training, and Expressed Interest in Training in These.

\begin{tabular}{|c|c|c|c|c|}
\hline \multirow[b]{2}{*}{ Alternative Medical Therapy } & \multirow{2}{*}{$\begin{array}{c}\text { Legitimate } \\
\text { Medical Practice }\end{array}$} & \multicolumn{2}{|c|}{ Amount of Training } & \multirow{2}{*}{$\begin{array}{l}\text { Interest in } \\
\text { Training }\end{array}$} \\
\hline & & Some & A Lot, Advanced & \\
\hline Nutrition and diet & 96 & 46 & 28 & 32 \\
\hline Counseling or psychotherapy & 94 & 34 & 23 & 11 \\
\hline Fitness and exercise & 91 & 45 & 28 & 26 \\
\hline Emotional support groups & 79 & 36 & 20 & 14 \\
\hline Biofeedback & 73 & 28 & 4 & 29 \\
\hline Acupuncture & 63 & 11 & 1 & 26 \\
\hline Herbal medicine & 54 & 35 & 5 & 30 \\
\hline Massage therapy & 54 & 17 & 4 & 21 \\
\hline Chiropractic & 53 & 4 & 0 & 9 \\
\hline Hypnotherapy & 52 & 14 & 4 & 10 \\
\hline Meditation & 51 & 34 & 10 & 26 \\
\hline Homeopathic medicine & 39 & 11 & 2 & 9 \\
\hline Traditional Chinese medicine & 38 & 13 & 1 & 14 \\
\hline Acupressure & 37 & 9 & 0 & 19 \\
\hline Chelation therapy & 35 & 7 & 1 & 7 \\
\hline Music therapy & 35 & 18 & 3 & 11 \\
\hline Cultural/folk medicine & 34 & 19 & 5 & 20 \\
\hline Dance/movement therapies & 32 & 15 & 3 & 10 \\
\hline Prayer/spiritual healing & 32 & 22 & 16 & 14 \\
\hline Megavitamin therapy & 28 & 14 & 2 & 6 \\
\hline Guided imagery & 25 & 10 & 6 & 6 \\
\hline Colon therapy & 24 & 4 & 1 & 4 \\
\hline Naturopathic medicine & 20 & 2 & 1 & 3 \\
\hline Macrobiotic diet & 19 & 7 & 1 & 4 \\
\hline Therapeutic touch & 19 & 7 & 3 & 8 \\
\hline Bioelectromagnetics & 18 & 2 & 0 & 4 \\
\hline Tai chi & 17 & 10 & 4 & 16 \\
\hline Ayurvedic medicine & 15 & 7 & 1 & 8 \\
\hline Aromatherapy & 12 & 7 & 2 & 7 \\
\hline Reiki & 4 & 1 & 2 & 1 \\
\hline
\end{tabular}

Note: Therapies are listed in order of perceived legitimacy. Total $n=143$; however, the number of responses to the individual therapies ranged from 136 to 141 for legitimacy and from 135 to 140 for training.

alternative medical therapy, resulting in 676 separate experiences (the 5 most frequently cited were fitness and exercise, nutrition and diet, prayer or spiritual healing, counseling or psychotherapy, and herbal medicine, Table 3), for an average of 5.7 different therapies experienced by those who reported using alternative medical therapies. If, as before, the top 5 most legitimate alternative medical therapies are removed from the analysis, $70 \%$ (100) of those respondents nevertheless reported 400 experiences, averaging 4 different therapies each. The $\mathrm{MD}$ and $\mathrm{PhD}$ respondents reported personal experience with significantly fewer (GLM $P=.047)$ therapies than the other degree respon- dents. This effect is consistent for both the full list of 30 practices and the 25 practices remaining when the 5 therapies most frequently classified as legitimate are removed from the analysis.

When respondents rated the effectiveness of the therapies with which they had experience, $87 \%$ of the experiences were rated as effective. Three percent were rated not effective, $10 \%$ were rated as unknown, and only $0.3 \%$ were rated as harmful. The latter group involved one experience each in chiropractic and megavitamin therapy.

The data on training and experience were further analyzed in relation to the respondents' own answers to question 1 in which therapies were eval- 
Table 3. Percentage of Respondents Reporting Personal Experience with and Perceived Effectiveness of Alternative Therapies.

\begin{tabular}{|c|c|c|c|c|c|c|c|c|}
\hline \multirow[b]{2}{*}{ Alternative Medical Therapy } & \multicolumn{4}{|c|}{ Personal Experience } & \multicolumn{4}{|c|}{ Consider Treatment Effective* } \\
\hline & MD & $\mathrm{PhD}$ & Other & Total & MD & $\mathrm{PhD}$ & Other & Total \\
\hline Fitness and exercise & 57 & 54 & 70 & 58 & 100 & 92 & 93 & 98 \\
\hline Nutrition and diet & 55 & 50 & 80 & 57 & 98 & 96 & 88 & 95 \\
\hline Prayer/spiritual healing & 33 & 31 & 55 & 36 & 84 & 80 & 91 & 84 \\
\hline Counseling or psychotherapy & 40 & 23 & 30 & 33 & 100 & 91 & 100 & 98 \\
\hline Herbal medicine & 27 & 31 & 40 & 30 & 65 & 87 & 88 & 77 \\
\hline Emotional support groups & 32 & 17 & 30 & 27 & 96 & 100 & 83 & 95 \\
\hline Meditation & 25 & 29 & 30 & 27 & 84 & 86 & 100 & 87 \\
\hline Massage therapy & 23 & 19 & 55 & 26 & 88 & 89 & 91 & 89 \\
\hline Biofeedback & 20 & 15 & 25 & 19 & 87 & 86 & 80 & 85 \\
\hline Chiropractic & 13 & 15 & 30 & 16 & 70 & 57 & 83 & 70 \\
\hline Cultural/folk medicine & 13 & 15 & 30 & 16 & 90 & 100 & 67 & 87 \\
\hline Acupuncture & 12 & 13 & 25 & 14 & 89 & 83 & 40 & 75 \\
\hline Acupressure & 8 & 10 & 25 & 11 & 83 & 60 & 80 & 75 \\
\hline Guided imagery & 9 & 13 & 15 & 11 & 86 & 83 & 67 & 81 \\
\hline Music therapy & 11 & 13 & 10 & 11 & 88 & 83 & 100 & 88 \\
\hline Traditional Chinese medicine & 7 & 17 & 15 & 11 & 80 & 63 & 67 & 69 \\
\hline Tai chi & 8 & 8 & 20 & 10 & 83 & 75 & 75 & 79 \\
\hline Hypnotherapy & 12 & 4 & 10 & 9 & 78 & 100 & 0 & 69 \\
\hline Ayurvedic medicine & 5 & 10 & 10 & 8 & 75 & 100 & 100 & 91 \\
\hline Homeopathic medicine & 5 & 8 & 15 & 8 & 75 & 100 & 67 & 82 \\
\hline Megavitamin therapy & 8 & 6 & 10 & 8 & 33 & 33 & 100 & 45 \\
\hline Aromatherapy & 7 & 2 & 15 & 6 & 100 & 100 & 100 & 100 \\
\hline Chelation therapy & 5 & 0 & 10 & 4 & 100 & 0 & 100 & 100 \\
\hline Therapeutic touch & 4 & 2 & 10 & 4 & 100 & 100 & 100 & 100 \\
\hline Colon therapy & 4 & 0 & 5 & 3 & 67 & 0 & 100 & 75 \\
\hline Dance/movement therapies & 3 & 2 & 10 & 3 & 100 & 100 & 100 & 100 \\
\hline Macrobiotic diet & 3 & 2 & 5 & 3 & 50 & 100 & 0 & 50 \\
\hline Reiki & 1 & 0 & 10 & 2 & 100 & 0 & 50 & 67 \\
\hline Bioelectromagnetics & 3 & 0 & 0 & 1 & 50 & 0 & 0 & 50 \\
\hline Naturopathic medicine & 0 & 0 & 5 & 1 & 0 & 0 & 100 & 100 \\
\hline
\end{tabular}

Note: Therapies are listed in order of percentage of total respondents with personal experience.

*The percentages given for effectiveness reflect only those respondents who have had personal experience with that therapy.

uated as to their perceived level of legitimacy. Sixty-five percent of the respondents reported experience with, training in, or an interest in receiving training in an activity which they themselves did not categorize as a legitimate medical practice.

\section{Attitudes}

Respondents were asked to rate on a 7-point scale their level of agreement or disagreement with statements related to general attitude, placebo effects, and the use of alternative medical practices (Table 4). A rating of 1 indicates strong agreement with the statement, a 7 indicates strong disagreement with the statement.
General Attitude

The statement "My general attitude toward alternative medicine is positive" was endorsed with a mean of 2.66. The PhD (mean $=2.44)$ and other degree $($ mean $=2.20)$ respondents agreed more strongly (GLM $P=.005$ ) than the MD respondents (mean $=2.93$ ) that their general attitude toward alternative medicine is positive. General attitude toward alternative medicine was positively correlated with the statement, "My attitude toward alternative medicine has changed substantially over the past few years." Those who felt positively about alternative medicine were more likely to have recently changed their attitudes $(r[\mathrm{n}=140]=0.531$, 


\begin{tabular}{|c|c|c|c|c|}
\hline \multirow[b]{2}{*}{ Attitudes } & \multicolumn{3}{|c|}{ Degree } & \multirow[b]{2}{*}{$\begin{array}{c}\text { Total } \\
\text { Mean (SD) }\end{array}$} \\
\hline & $\begin{array}{c}\text { MD } \\
\text { Mean (SD) }\end{array}$ & $\begin{array}{c}\mathrm{PhD} \\
\text { Mean (SD) }\end{array}$ & $\begin{array}{c}\text { Other } \\
\text { Mean (SD) }\end{array}$ & \\
\hline \multicolumn{5}{|l|}{ General attitudes } \\
\hline $\begin{array}{l}\text { Both the mind and body must be treated for the } \\
\text { patient to regain complete health }(\mathrm{n}=142)\end{array}$ & $1.68(0.90)$ & $1.72(0.88)$ & $1.60(0.82)$ & $1.68(0.88)$ \\
\hline $\begin{array}{l}\text { The mind-body connection to health also contains an } \\
\text { important spiritual component }(\mathrm{n}=142)\end{array}$ & $1.97(0.99)$ & $2.27(1.55)$ & $2.00(1.12)$ & $2.08(1.23)$ \\
\hline $\begin{array}{l}\text { My general attitude toward alternative medicine is } \\
\text { positive }(n=142)\end{array}$ & $2.93(1.25)$ & $2.44(1.53)$ & $2.20(1.20)$ & $2.66(1.37)$ \\
\hline $\begin{array}{l}\text { My attitude toward alternative medicine has changed } \\
\text { substantially over the past few years }(n=141)\end{array}$ & $3.55(1.69)$ & $3.26(1.77)$ & $3.40(1.79)$ & $3.43(1.73)$ \\
\hline \multicolumn{5}{|l|}{ Placebo effects } \\
\hline $\begin{array}{l}\text { Alternative medical therapies are mainly useful for their } \\
\text { placebo effects instead of as specific remedies } \\
(\mathrm{n}=143)\end{array}$ & $4.63(1.34)$ & $4.92(1.49)$ & $4.80(1.28)$ & $4.75(1.38)$ \\
\hline $\begin{array}{l}\text { Any improvement perceived by the patient using } \\
\text { alternative medical therapies is mainly due to the } \\
\text { alternative therapists empathy, time spent with the } \\
\text { patient and/or perceived individualized treatment } \\
(\mathrm{n}=143)\end{array}$ & $4.60(1.36)$ & $5.17(1.39)$ & $4.95(1.50)$ & $4.84(1.40)$ \\
\hline $\begin{array}{l}\text { If a patient improves because of a placebo effect, the } \\
\text { patient has not really improved, even if the } \\
\text { improvements are verified by clinical findings } \\
(n=140)\end{array}$ & $5.64(1.27)$ & $5.34(1.42)$ & $5.10(1.21)$ & $5.46(1.32)$ \\
\hline \multicolumn{5}{|l|}{ Using alternative medical therapies } \\
\hline $\begin{array}{l}\text { Patients with an untreatable condition should be } \\
\text { encouraged to seek alternative therapies }(\mathrm{n}=141)\end{array}$ & $3.66(1.58)$ & $2.63(1.51)$ & $3.00(1.52)$ & $3.21(1.61)$ \\
\hline $\begin{array}{l}\text { A physician should not advise any patient to try } \\
\text { alternative therapies because it might raise false } \\
\text { hopes }(\mathrm{n}=142)\end{array}$ & $4.88(1.38)$ & $5.28(1.31)$ & $5.00(1.38)$ & $5.03(1.36)$ \\
\hline
\end{tabular}

All items were rated on a 7-point scale: $1=$ strongly agree, $7=$ strongly disagree. Items are listed within category in order of total sample's decreasing agreement.

$P<.001)$. The most strongly agreed on statement in the questionnaire was "Both the mind and body must be treated for the patient to regain complete health" (mean = 1.68). There was also strong agreement with a related statement, "The mindbody connection to health,[sic] also contains an important spiritual component" (mean $=2.08$ ).

Women (mean $=2.91$ ) agreed more strongly $($ GLM $P=.008)$ than did men $($ mean $=3.78)$ with the statement that their attitudes toward alternative medicine had changed substantially during the past few years. Women respondents also agreed more strongly than the male respondents with the statements indicating the need to treat both mind and body for complete health (female mean $=1.43$; male mean $=1.86$; GLM $P=.01)$ and the inclusion of a spiritual component in the mind-body connection to health (female mean $=1.65$; male mean $=2.38$; GLM $P=.003)$. African Americans $($ mean $=1.85)$ agreed more strongly $($ GLM $P=$
$.045)$ with the latter statement than the other ethnic groups $($ mean $=2.52)$.

\section{Placebo Effects}

The respondents tended to disagree with statements that attributed the effectiveness of alternative medical therapies to only placebo (mean $=$ 4.75 ) or therapist (mean $=4.84$ ) effects. The female respondents (female mean $=5.13$; male mean $=4.51 ;$ GLM $P=.018)$ and the African American respondents (African American mean = 5.00; other ethnic groups mean $=4.30$; GLM $P=$ .023 ) disagreed more strongly with the statement attributing the effectiveness of alternative therapies to mainly placebo effects. The $\mathrm{PhD}$ respondents $($ mean $=5.17)$ disagreed more strongly (GLM $P=$ $.02)$ than the other degree (mean $=4.95$ ) or $\mathrm{MD}$ (mean $=4.60)$ respondents with a statement that attributed effectiveness to therapist effects. Respondents disagreed with the statement that clini- 
cally verified improvements, attributed to a placebo effect, should not be viewed as real improvements (mean $=5.46)$. African American respondents $($ mean $=5.64)$ disagreed more strongly (GLM $P=$ $.005)$ with this concept than the other ethnic groups $($ mean $=5.00)$.

\section{Using Alternative Medical Therapies}

There was a substantial discrepancy between the responses of the $\mathrm{MD}$ (mean = 3.66) and $\mathrm{PhD}$ (mean $=2.63)$ respondents regarding a statement which suggested that patients with untreatable conditions be encouraged to seek alternative therapies. There was a significant difference (GLM $P=.004$ ), because $27 \%$ of the $\mathrm{PhD}$ respondents strongly agreed compared with only $4 \%$ of the MD respondents. In response to a related concept, respondents disagreed with the statement, "Physicians should not advise patients to try alternative therapies because it might raise false hopes" (mean $=5.03$ ). The African American respondents (mean $=5.23$ ) disagreed more strongly (GLM $P=.031$ ) with this statement than the other ethnic groups (mean = 4.69).

\section{Discussion}

Any discussion of alternative medical therapies must be tempered with the realization that these therapies span a broad range of activities. For the purpose of this study, the phrase "alternative/ complimentary medicine or therapies" referred to any substance, activity, or practice not usually taught in detail or recommended to a medical student. This definition was used with the knowledge that more than 60 medical schools currently offer courses covering these topics. Any future definition might require modification. Since the completion of this study, the results of the panel on definition and description at the Office of Alternative Medicine (now the National Center for Complementary and Alternative Medicine) defined complimentary and alternative medicine as "... a broad domain of healing resources that encompasses all health systems, modalities, and practices and their accompanying theories and belief, other than those intrinsic to the politically dominant health system ...," and those "... boundaries ... are not always sharp or fixed." ${ }^{16}$ With this caveat in mind, the results of this survey indicate that these respondents have had substantial exposure to alternative and complemen- tary therapies, appear to be interested in gaining further knowledge about these therapies, and overall have generally positive attitudes toward alternative medical practices.

The findings that $65 \%$ of the respondents have been involved with or have an interest in an alternative or complementary therapy which they themselves do not consider a legitimate medical practice and that $87 \%$ of the personal experiences with an alternative or complementary therapy have been viewed as effective further indicate that this medical school faculty has a positive attitude toward, considerable knowledge about, and experience with alternative and complementary therapies.

It might be argued that the inclusion of some well-respected alternative therapies (such as nutrition and diet) into a survey such as this would yield an erroneously high impression of respondent experience with alternative therapies. Removal of the top five therapies in this study, however, only reduced the $85 \%$ level of overall experience to $71 \%$, which nevertheless indicates a substantial level of interest. The $71 \%$ personal experience rate is considerably higher than the $52 \%$ reported by Burg et $\mathrm{al}^{13}$ in their survey of experience with alternative practices by a medical school faculty. This higher rate might be attributable to the inclusion in our study of more forms of complementary and alternative therapies, especially in that every one of the 30 alternative practices listed in the present study was checked for personal experience at least once. It might also be related to the higher survey response rate in our study (72\%), compared with the Burg et al study (59\%), or the variability of the response rate across the different schools of the health science center. The larger number of complementary and alternative practices in our questions and our higher response rate could also account for some of the differences found regarding personal experience between our results and those of the other physician surveys. ${ }^{5,7}$

The response to a broad statement such as " $\mathrm{My}$ general attitude toward alternative medicine is positive" must be viewed cautiously. Nonetheless, such an answer can help to describe the general atmosphere that surrounds the topic. A high level of agreement with that statement and an $85 \%$ response indicating some level of previous training, desire for future training, or previous personal experience indicate the level of awareness toward 
alternative medical therapies at this particular institution.

The first three questions of this survey were modeled after a study of family physicians by Berman and colleagues. ${ }^{5}$ For about $60 \%$ of the therapies that were common to both studies, the proportion of respondents rating alternative therapies as legitimate medical practices were within $10 \%$ of each other in the two studies. With the exception of herbal medicine, the Berman et al study respondents, all practicing physicians, reported a higher percentage of training in alternative therapies than did the respondents in this study. In our study, a private practice was reported by only $29 \%$ of all respondents, but almost one-half of the MD respondents. If there is a tendency for practicing physicians to seek training in alternative therapies, then this tendency might explain Berman and colleagues' higher percentage of respondents who report such training.

Our data suggest that as a group those who have a positive attitude toward alternative medical practices have had a recent attitude change toward the positive. This change might reflect growing acceptance of alternative and complementary therapies, reaction to patients' increasing use of these therapies, or an increase in the amount of information available on the subject.

Clinical caution on the part of MD respondents might explain some of the difference between their responses and those of the $\mathrm{PhD}$ respondents to the two attitude statements related to referrals for alternative practices. The $\mathrm{PhD}$ respondents agreed more strongly than the MD respondents with the statement which suggested that patients with untreatable conditions be encouraged to seek alternative therapies. These respondents also disagreed more strongly than the MD respondents with the statement suggesting that physicians should not advise patients to try alternative therapies because it might raise false hopes. Although these two attitude statements describe situations of an extreme nature, the data from our respondents are nonetheless consistent with the referral rates to alternative providers that have been reported in other studies. $^{6,7,13}$

Among our respondents, degree, sex, and ethnicity are related mainly to the strength of opinions on the general attitudes and use of alternative therapies. Although there appear to be some demographic factors that are related to the attitude or knowledge about an individual alternative or complementary therapy, the sample size and composition and the overall diversity of such therapies make further interpretation of these factors difficult at this time.

Even though this study sample is small, our data relate to other similarly small samples, and a picture of attitudes toward alternative and complementary medical practices seems to be emerging. For example, the analysis of our data with the five most highly ranked therapies removed nonetheless indicates positive attitudes similar to those of other studies. ${ }^{5,14}$ Because the use of alternative therapies is often related to prevention, the positive attitudes might be a reflection of the institutional mission to train primary care physicians. These results might, however, also reflect a generally increasing interest in alternative medicine, as is seen in the results of recent surveys, as well as in the increase in the number of managed care companies that now incorporate payment for certain alternative practices into their insurance coverage. ${ }^{17,18}$ In addition, a growing number of state governments are considering legislation pertaining to the practice of such therapies by health care professionals. Indeed, some of the therapies, eg, counseling or psychotherapy, and chiropractic, and massage in some states, are already legislated. With increased acceptance of insurance coverage for alternative and complementary therapies and high levels of use by the general population, there will be a greater need for the primary care physician to be familiar with these practices, as well as with their patients' use of them. Medical school faculty need to prepare themselves to address complementary and alternative modalities in their teaching to ensure that graduates are prepared for the realities of patient preferences and behaviors.

We wish to thank Alan Marks, Department of Psychology, and Ida Rousseau-Mukenge, Department of Sociology, Morehouse College, for their statistical assistance and review contributions.

\section{References}

1. Eisenberg DM, Kessler RC, Foster C, Norlock FE, Calkins DR, Delbanco TL. Unconventional medicine in the United States. Prevalence, costs, and patterns of use. N Engl J Med 1993;328:246-52.

2. Eisenberg DM, Davis RB, Ettner SL, et al. Trends in alternative medicine use in the United States, 1990-1997: results of a follow-up national survey. JAMA 1998;280:1569-75. 
3. Elder NC, Gillcrist A, Minz R. Use of alternative health care by family practice patients. Arch Fam Med 1997;6:181-4.

4. Astin JA. Why patients use alternative medicine: results of a national study. JAMA 1998;279:1548-53.

5. Berman BM, Singh BK, Lao L, Singh BB, Ferentz KS, Hartnoll SM. Physicians attitudes toward complementary or alternative medicine: a regional survey. J Am Board Fam Pract 1995;8:361-6.

6. Cherkin D, MacCornack FA, Berg AO. Family physicians' views of chiropractors: hostile or hospitable? Am J Public Health 1989;79:636-7.

7. Borkan J, Neher JO, Anson O, Smoker B. Referrals for alternative therapies. J Fam Pract 1994;39:54550.

8. Goldstein MS, Sutherland CE, Jaffe DT, Wilson J. Holistic physicians and family practitioners: an empirical comparison. Fam Med 1987;19:281-6.

9. Nishiwaki R, Morton A, Bouchard C, Peters JA, Jarvis WT. Perceived health quackery use among patients. West J Med 1990;152:87-9.

10. Boucher TA, Lenz SK. An organizational survey of physicians' attitudes about and practice of complementary and alternative medicine. Alternative Therapies Health Med 1998;4(6):59-65.

11. Ernst E, Resch K-L, White AR. Complementary medicine. What physicians think of it: a metaanalysis. Arch Intern Med 1995;155:2405-8.

12. "Alternative medicine" delivery in curriculum of U.S. medical schools. In: 1998-99 AAMC Curriculum Directory. Washington, DC: Association of American Medical Colleges, 1998.

13. Burg MA, Kosch SG, Neims AH, Stoller EP. Personal use of alternative medicine therapies by health science center faculty. JAMA 1998;280:1563.

14. Reilly DT. Young doctor's views on alternative medicine. BMJ (Clin Res Ed)1983;287:337-9.

15. SPSS for Windows, version 8.0; release 8.0.2. Chicago: SPSS, Sept 23, 1998.

16. Defining and describing complementary and alternative medicine. Panel on Definitions and Description, CAM Research Methodology Conference, April 1995. Altern Ther Health Med 1997;3(2):49_ 57.

17. Moore NG. A review of reimbursement policies for alternative and complementary therapies. Altern Ther Health Med 1997;3:26-31.

18. Pelletier KR, Marie A, Krasner M, Haskell WL. Current trends in the integration and reimbursement of complementary and alternative medicine by managed care, insurance carriers, and hospital providers. Am J Health Promot 1997;12:112-22. 